\title{
THỰC TRANG VỀ TỰ KHÁM VÚ CỦA PHỤ NỮ XÃ TIÊN PHƯƠ'NG NĂM 2020
}

\author{
Nguyễn Thị Diễm Hương ${ }^{1,2, \bowtie, ~ V u ̃ ~ T h i ̣ ~ N g a ̂ n ¹ ~}$ \\ ${ }^{1}$ Viện Đào tạo YHDP và YTCC, Trường Đại học Y Hà Nội \\ ${ }^{2}$ Trường Đại học Y Hà Nội
}

Nghiên cứu nhằm mô tả về thực hành tự khám vú (BSE) và các rào cản trong việc thực hành tự khám vú trên nhóm phụ nữ từ 18 tuổi trở lên tại xã Tiên Phương, huyện Chương Mỹ, Thành phố Hà Nội năm 2020. Sử dụng phương pháp mô tả cắt ngang và bộ câu hỏi được thiết kế sãn để phỏng vấn 353 phụ nữ . Kết quả cho thấy tỷ lệ thực hành tự khám vú còn thấp (47,5\%), đặc biệt là đúng tần suất còn rất thấp $(3,7 \%)$. Lý do tự báo cáo là 70,9\% thấy không có vấn đề gì ở vú, 60,3\% không biết cách thực hiện. Hồi quy đơn biến cho thấy trình độ học vấn, số con và nghề nghiệp có mối liên quan có ý nghĩa thông kê $(p<0,05)$ đến việc thực hành tự khám vú. Cần tăng cường các hoạt động truyền thông giáo dục sức khoẻ về ung thư vú và tự khám vú .

Từ khóa: Tự khám vú, BSE, ung thư vú.

\section{I. ĐẠT VÂN ĐÊ}

Ngày nay, ung thư vú là một trong những loại ung thư có tỷ lệ mắc cao nhất ở phụ nữ trên toàn cầu. ${ }^{1}$ Ở Việt nam, ung thư vú đứng đầu về tỷ lệ mắc và tử vong do ung thư ở nữ giới. ${ }^{2}$ Nhờ sự phát triển của khoa học công nghê, ngày nay tử vong do ung thư vú đã có thể ngăn ngừa nếu được chẩn đoán sớm,ước tính 4,4 triệu phụ nữa bị ung thư vú được chẩn đoán từ hơn 5 năm trước hiện còn sống. ${ }^{3}$ Chụp $X Q$ vú, siêu âm vú, khám lâm sàng và tự khám vú (BSE) được xem những biện pháp hiệu quả trong việc phát hiện sớm ung thư vú. ${ }^{4}$ Mặc dù có nhiều ý kiến trái chiều và hiệu quả của tự khám vú khi áp dụng riêng lẻ trong việc phát hiện sớm ung thư vú nhưng đây vẫn là một công cụ sàng lọc phát hiện sớm ung thư vú ở các nước đang phát triển vì không tốn chi phí, có thể triển khai trên diện rộng và kỹ thuật đơn giản. ${ }^{5}$ Theo nghiên cứu Giridhara và cộng sự năm 2011 cho

Tác giả liên hệ: Nguyễn Thị Diễm Hương

Viện Đào tạo YHDP và YTCC, Trường Đại học Y Hà Nội

Email: diemhuong@hmu.edu.vn

Ngày nhận: 02/04/2021

Ngày được chấp nhận: 30/07/2021 thấy nếu phụ nữ thực hành tự khám vú thường xuyên sẽ quen với cấu trúc bình thường của vú có khả năng khám sàng lọc lâm sàng và siêu âm vú cao hơn so với nhóm phụ nữ còn lại. ${ }^{5}$ Có nhiều yếu tố là ngăn cản của việc thực hành tự khám vú của phụ nữ bao gồm nhận thức vềxã hội và văn hoá của việc tự khám vú (xấu hổ, sợ hãi khi phát hiện khi khối u), nhận thức hạn chế về bệnh (không biêt cách thực hiện, nghĩ rằng bản thân không bao giờ bị bệnh). ${ }^{6}$ Tại Việt Nam, có nhiều nghiên cứu về ung thư vú nhưng các thông tin về rào cản trong thực hành tự khám vú còn hạn chế, đặc biệt tại xã Tiên Phương, huyện Chương Mỹ, thành phố Hà Nội. Đây là một xã nằm gần trung tâm huyện, địa hình xã một nửa là đồng bằng và nửa là đồi núi. Vì các lí do trên, chúng tôi thực hiện nghiên cứu với mục đích mô tả thực hành tự khám vú và các rào cản trong thực hành tự khám vú của phụ nữ tại xã Tiên Phương năm 2020.

\section{II. ĐÓl TƯỢNG VÀ PHƯƠNG PHÁP}

\section{1. Đối tượng}

Đối tượng nghiên cứu là phụ nữ từ 18 tuổi trở lên, được xác định từ danh sách của Hội 
phụ nữ và danh sách sinh viên từ hội khuyến học xã Tiên Phương.

\section{Tiêu chuẩn lựa chọn}

- Phụ nữ đang sinh sống trên địa bàn xã Tiên Phương, huyện Chương Mỹ, thành phố Hà Nội trong thời gian tiến hành nghiên cứu.

- Có khả năng đọc hiểu, cung cấp thông tin theo yêu cầu nghiên cứu.

- Đồng ý tham gia nghiên cứu.

\section{Tiêu chuẩn loại trừ}

- Đối tượng đang mắc các bệnh cấp tính.

\section{Phương pháp}

\section{Thiết kế nghiên cứu}

Nghiên cứu mô tả cắt ngang.

\section{Thò̀i gian nghiên cứu}

Tháng 8/2019 - 6/2020

\section{Địa điểm nghiên cứu}

Xã Tiên Phương, huyện Chương Mỹ, Thành Phố Hà Nội.

\section{Cõ̃ mẫu}

Được tính toán theo công thức tính cỡ mẫu cho ước lượng một tỷ lệ trong quần thể.

$$
\mathrm{n}=\mathrm{Z}^{2} 1-\alpha / 2 \frac{p(1-p)}{d 2}
$$

Trong đó $p=0,37$ là tỷ lệ người dân có kiến thức về tầm soát ung thư vú tốt trong nghiên cứu của Đỗ Thị Thanh Toàn 2019.

Tính ra cỡ mẫu tối thiểu cho nghiên cứu là 358, tuy nhiên do thời gian thu thập số liệu hạn chế và ảnh hưởng bởi dịch bệnh COVID-19 nên số lượng đối tượng đã điều tra là 353 người.

\section{Chọn mẫu}

Nghiên cứu áp dụng kỹ thuật chọn mẫu thuận tiện, đảm bảo các tiêu chuẩn lựa chọn và tiêu chuẩn loại trừ.

\section{Công cụ thu thập số liệu}

Số liệu được thu thập thông qua bộ câu hỏi được thiết kế sã̃n dựa trên các khuyến cáo của Tổ chức y tế thế giới, theo khuyến cáo thì phụ nữ từ 20 tuổi trở lên nên thực hành tự khám vú mỗi tháng một lần ngay sau khi kết thúc kỳ kinh nguyệt. Bộ công cụ thu thập các thông tin của đối tượng nghiên cứu về đặc điểm cá nhân, nhận thức về ung thư và tự khám vú, thực hành tự khám vú và rào cản của thực hành tự khám vú, nguồn thông tin về tự khám vú. Thông tin cá nhân bao gồm: tuổi, trình độ học vấn, nghề nghiệp, số con trong gia đình, thu nhập. Nhận thức về ung thư vú và tự khám vú bao gồm các câu hỏi: Đã từng nghe đến ung thư vú hay chưa? Tuổi bắt đầu tự khám vú? Đã từng thực hiện tự khám vú hay chưa? Lý do không thực hiện tự khám vú?

\section{Phương pháp thu thập số liệu}

Phỏng vấn trực tiếp dựa trên bộ công cụ đã được thiết kế sãn.

\section{Xử lý số liệu}

Số liệu làm sạch, mã hoá và được nhập bằng phần mềm Kobotolbox và phân tích bằng SPSS 20. Sử dụng các thuật toán thông kê để mô tả các biến số (đặc điểm cá nhân, nhận thức của đối tượng về ung thư vú và tự khám vú).

\section{4. Đạo đức nghiên cứu}

Nghiên cứu được triển khai tại xã Tiên Phương với sự chấp thuận của lãnh đạo địa phương. Nghiên cứu sử dụng kỹ thuật phỏng vấn để thu thập thông tin, không làm ảnh hưởng đến sức khoẻ của đối tượng. Các đối tượng tham gia nghiên cứu là hoàn toàn tự nguyện, được cung cấp thông tin đầy đủ về mục đích và nội dung nghiên cứu. Các thông tin thu thập được chỉ dành cho mục đích nghiên cứu khoa học và phục vụ sức khoẻ cộng đồng, không sử dụng vì mục đích nào khác. Trong quá trình phỏng vấn các đối tượng có quyền tử chối bất cứ câu hỏi nào mà họ không mong muốn trả lời 


\section{KẾT QUẢ}

1. Thông tin chung về đối tượng nghiên cứu

Bảng 1. Một số đặc điểm của đối tượng nghiên cứu

\begin{tabular}{|c|c|c|c|}
\hline \multicolumn{2}{|c|}{ Thông tin chungcủaphụnũ } & \multirow{2}{*}{$\begin{array}{c}\mathbf{n} \\
150\end{array}$} & \multirow{2}{*}{$\frac{\text { Tỷlệ \% }}{42,5 \%}$} \\
\hline \multirow{4}{*}{ Độ tuổi } & $18-29$ & & \\
\hline & $30-39$ & 96 & $27,2 \%$ \\
\hline & $40-49$ & 57 & $16,1 \%$ \\
\hline & Trên 50 tuổi & 50 & $14,2 \%$ \\
\hline \multirow{4}{*}{ Trình độ học vấn } & Không đi học/Tiểu học & 28 & $7,9 \%$ \\
\hline & THCS/THPT & 221 & $62,6 \%$ \\
\hline & Trung cấp/ cao đẳng & 80 & $22,7 \%$ \\
\hline & Đại học/Sau đại học & 24 & $6,8 \%$ \\
\hline \multirow{3}{*}{ Tình trạng hôn nhân } & Đang sống với chồng & 306 & $86,7 \%$ \\
\hline & Chưa từng kết hôn & 41 & $11,6 \%$ \\
\hline & Ly thân/li hôn/goá & 6 & $1,7 \%$ \\
\hline \multirow{4}{*}{ Số con } & Chưa có con & 52 & $14,7 \%$ \\
\hline & Một con & 63 & $17,8 \%$ \\
\hline & Hai con & 155 & $43,9 \%$ \\
\hline & Từ ba con trở lên & 83 & $23,5 \%$ \\
\hline \multirow{5}{*}{ Nghề nghiệp } & Nông dân & 88 & $24,9 \%$ \\
\hline & Công dân & 130 & $26,9 \%$ \\
\hline & Kinh doanh/lao động tự do & 77 & $21,8 \%$ \\
\hline & Cán bộ/viên chức & 24 & $6,8 \%$ \\
\hline & Nội trợ/sinh viên & 34 & $17,6 \%$ \\
\hline
\end{tabular}

Tổng số có 353 phụ nữ đã tham gia vào nghiên cứu với độ tuổi từ 18 tuổi trở lên, trong đó nhóm tuổi 18 - 29 tuổi chiếm tỷ lệ cao nhất là 42,5\%. Thấp nhất là nhóm tuổi trên 50 tuổi (chiếm 14,2\%). Học vấn của các đối tượng tham gia khá đa dạng và tập trung phần lớn vào nhóm học vấn THCS và THPT (28,3\% và $34,3 \%)$. Đa phần phụ nữ tham gia nghiên cứu đã kết hôn $(86,7 \%)$ và tỷ lệ có 2 con trở lên cao hơn so với nhóm có một con. Thu nhập của phần lớn hộ gia đình khoảng 10-19 triệu/tháng (73.8\%). Hơn một nữa phụ là công nhân và nông dân (26,9\% và $24,9 \%)$. Tỷ lệ phụ nữ là cán bộ, viên chức khá thấp 6,8\%. (Bảng 1) 


\section{Nhận thức về ung thư vú và tự khám vú}

Bảng 2. Nhận thức về ung thư vú và tự khám vú

\begin{tabular}{llll}
\hline \multicolumn{1}{c}{ Nhận thức về ung thư vú là tự khám vú } & $\mathbf{n}$ & Tỷ lệ \% \\
\hline Đã từng nghe đến ung thư vú $(\mathrm{n}=353)$ & 341 & $96,6 \%$ \\
\hline Đã từng nghe đến tự khám vú $(\mathrm{n}=341)$ & 189 & $55,4 \%$ \\
\hline Biết tần suất tự khám vú là 1 lần/tháng & 89 & $47,1 \%$ \\
\hline Biết thời điểm tự khám vú là sau kì kinh & 41 & $21,7 \%$ \\
\hline Biết độ tuổi tự khám vú là từ 20 tuổi & 98 & $51,9 \%$ \\
\hline
\end{tabular}

96,6\% phụ nữ đã từng nghe đến ung thư vú nhưng chỉ có hơn một nửa trong số đó $(55,4 \%)$ là nghe đến kỹ thuật tự khám vú để phát hiện khối u. Kiến thức về tự khám vú của các phụ nữ đã từng nghe đến kỹ thuật này cũng khá thấp, khoảng một nửa $(51,9 \%)$ trong số đó biết tuổi bắt đầu tự khám vú là từ 20 tuổi, 47,1\% biết tần suất của kỹ thuật tự khám vú là 1 tháng/1 lần và chỉ có $21,7 \%$ phụ nữ biết thời điểm thực hiện tự khám vú là sau kỳ kinh nguyệt vài ngày. (Bảng 2)

\section{Thực hành về tự khám vú}

Mặc dù 96,6\% phụ nữ đã từng nghe đến ung thư vú nhưng chỉ khoảng một nửa $(47,5 \%)$ trong số đó đã từng thực hiện tự khám vú. Trong số những người đã thực hiện tự khám vú chỉ có 6 người $(3,7 \%)$ là thực hiện tự khám vú hàng tháng.

Học vấn, nghề nghiệp và số con của phụ nữ có mối liên quan có ý nghĩa thông kê với việc thực hành tự khám vú $(p<0,05)$.

\section{Nguồn thông tin về thực hành tự khám vú}

Bảng 3. Nguồn thông tin thực hành tự khám vú $(\mathrm{n}=162)$

\begin{tabular}{cccc}
\hline Nguồn thông tin & $\mathbf{n}$ & Tỷ lệ $\%$ \\
\hline Tivi & 24 & 14,8 \\
\hline Internet & 126 & $77,8 \%$ \\
\hline Sách/báo/tạp chí & 14 & $8,6 \%$ \\
\hline Người thân/bạn bè & 16 & $9,9 \%$ \\
\hline Nhân viên y tế & 1 & $0.6 \%$ \\
\hline
\end{tabular}

Trong số những người đã thực hiện tự khám vú thì nguồn thông tin chủ yếu đến từ Internet $(77,8 \%)$, tiếp đến là từ Tivi $(14,8 \%)$. Chỉ có một phụ nữ $(0,6 \%)$ tham khảo thông tin từ các cán bộ y tế. (Bảng 3 ) 


\section{Rào cản thực hành tự khám vú}

Bảng 4. Lý do không tụ̣ khám vú $(n=179)$

\begin{tabular}{cccc}
\hline Lý do không tự khám vú & $\mathbf{n}$ & Tỷ lệ \% \\
\hline Không thấy có vấn đề gì ở vú & 127 & $70,9 \%$ \\
\hline Không biết cách thực hiện & 108 & $60,3 \%$ \\
\hline Thấy xấu hổ/không thoải mái & 18 & $10,1 \%$ \\
\hline Thấy không cần thiết & 18 & $10,1 \%$ \\
\hline Không có thời gian & 22 & $12,3 \%$ \\
\hline Quên & 15 & $8,4 \%$ \\
\hline
\end{tabular}

Trong số những những phụ nữ không thực hành tự khám vú tại nhà thì lý do chính "Không thấy có vấn đề gì ở vú" chiếm 70,9\%. Tiếp theo là lý do liên quan đến kiến thức, $60,3 \%$ phụ nữ báo cáo là không biết cách thực hành tự khám vú tại nhà. Một số lý do khác như cảm thấy không thoải mái hay thấy tự khám vú không thực sự cần thiết, không có thời gian chiếm tỷ lệ lần lượt (10,1\%; 10,1\%;12,3\%). (Bảng 4)

\section{BÀN LUẬN}

Nghiên cứu này được thực hiện để mô tả việc thực hành tự khám vú và rào cản trong việc thực hành tự khám vú ở phụ nữ xã Tiên Phương. Trong nghiên cứu trước của Đỗ Thị Thanh Toàn và cộng sự năm 2017 trên đối tượng là phụ nữ vùng núi phía Bắc Việt Nam cho thấy tỷ lệ thực hành tự khám vú là 13,8\% và trong nghiên cứu của Đỗ Quang Tuyền và cộng sự thực hiện trên đối tượng là nữ công nhân tại 2 thành phố lớn là Hà Nội là Thành phố Hồ Chí Minh năm 2016 thì tỷ lệ thực hành tự khám vú hàng tháng là $15,2 \% .^{7,8}$ Nghiên cứu của chúng tôi cho thấy mặc dù $47,5 \%$ phụ nữ báo cáo đã từng thực hành tự khám vú nhưng chỉ có 3,7\% là thực hiện hàng tháng trong 12 tháng qua. Kết quả này cũng tương đương như một số nghiên cứu khác ${ }^{9,10}$ cho thấy thực hành tự khám vú hàng tháng hiện nay là khá là thấp. Điều này có thể do suy nghĩ của đối tượng tham gia là họ cảm thấy vẫn khoẻ mạnh và việc tự khám vú là không cần thiết.

Bên cạnh đó, trong nhóm phụ nữ thực hiện tự khám vú thì nguồn thông tin chủ yếu đến từ Internet và tiếp đến là Tivi (lần lượt là 77,8 và $14,8 \%$ ). Trong khi đó nguồn thông tin đến từ các tài liệu in ấn thì rất thấp, cụ thể chỉ có 8,6\% phụ nữ báo cáo đọc được thông tin về tự khám vú từ sách/báo/tạp chí. Kết quả này khá khác biệt so với một số nghiên cứu được thực hiện ở Malaysia khi phần lớn thông tin mà đối tượng có được đến từ các tài liệu in ấn hoặc Tivi. 9,11

Kết quả cũng cho thấy trình độ học vấn, nghề nghiệp và số con có mối liên quan đến thực hành tự khám vú $(p<0,05)$. Kết quả này khá tương đồng so với kết quả của Đỗ Quang Tuyền năm 2016. ${ }^{8}$

Trong nghiên cứu này, lý do chính cho việc không thực hành tự khám vú là đối tượng không thấy có vấn đề gì ở vú $(70,9 \%)$ và tiếp theo là do không biết cách thực hiện tự khám vú $(60,3 \%)$. Rất nhiều người trẻ tin rằng ung thư vú chỉ xuất hiện ở những phụ nữ cao tuổi và do đó họ không phải là người có nguy cơ mắc ung thư vú. ${ }^{4}$ Kết quả này khá tương đồng 
với nghiên cứu của Mehrnoosh Akhtari-Zavare (2012) trên đối tượng là sinh viên nữ và và nghiên cứu của Avci (2008). ${ }^{4,10}$

"Không có thời gian thực hiện", "tự khám vú không cần thiết", "không thoải mái khi thực hiện" cũng là những rào cản thực hành tự khám vú ở phụ nữ xã Tiên Phương, huyện Chương Mỹ, thành phố Hà Nội năm 2020.

\section{Hạn chế của nghiên cứu}

Nghiên cứu của chúng tôi chưa đảm bảo được cỡ mẫu tối thiểu do tình hình dịch bệnh nên chưa khái quát hoá được kết quả cho toàn bộ phụ nữ của xã. Ngoài ra do điều kiện chưa cho phép nên không tiến hành thêm phỏng vấn định tính để tìm hiểu sâu về các rào cản thực hành tự khám vú tại xã Tiên Phương.

\section{KẾT LUẬN}

Nghiên cứu thực hiện trên 353 phụ nữ từ 18 tuổi trở lên tại xã Tiên Phương cho thấy tỷ lệ thực hành tự khám vú còn thấp, đặc biệt là việc thực hành đúng tần suất còn rất thấp. Học vấn, số con, nghề nghiệp có liên quan đến thực hành tự khám vú. Không thấy vấn đề ở vú và không biết cách thực hiện tự khám vú là 2 lý do chính mà đối tượng tự báo cáo dẫn đến không thực hiện tự khám vú. Như vậy việc tăng cường truyền thông giáo dục sức khoẻ các kiến thức về tự khám vú cho phụ nữ tại xã Tiên Phương là việc làm vô cùng cần thiết giúp cho đối tượng có kiến thức tốt hơn và từ đó thái độ tích cực về tự khám vú.

\section{TÀI LIẸU THAM KHẢO}

1. Clegg LX, Reichman ME. Impact of socioeconomic status on cancer incidence and stage at diagnosis: selected findings from the surveillance, epidemiology, and end results: National Longitudinal Mortality Study. Cancer Causes Control. 2009;20:417-435.

2. Hoang Van Minh, Tran Van Thuan, Xiao- ou Shu. Scientific Evidence for Cancer Control in Vietnam. Cancer Control. 2019;26:1-2.

3. Yazdani F. The effects of yoga on sympyom scales quality of life in breast cancer patients undergoing radiotherapy. Iran $\mathrm{J}$ Breast Cancer. 2015;7(4):33-42.

4. Avci IA. Factors associated with breast self-examination practices and beliefs in female workers at a Muslim Community. Eur J Oncol Nurs. 2008;12:127-133.

5. Giridhara RB, Goleen S, Sharon BC. Breast cancer screening among females in Iran and recommendation for improved practice: A review. Asian Pac J Cancer Prev. 2011;12:1647-1755.

6. Fariba Tabari, Reyhaneh Abbaszadeh, Sedigheh Tobari. Barriers of breast selfexamination: A review study from Iranian researchers. Bali Med J. 2017;6(3):562-568.

7. Do Thi Thanh Toan, Luu Ngoc Hoat, Luu Ngoc Minh. Knowledge, attitude and practice regarding breast cancer early detection among women in a mountainous area in northern Vietnam. Cancer Control. 2019;26(1).

8. Tuyen DQ, Dung TV, Dong HV, Kien TT. Breast selfexamination: knowledge and practice among female textile workers in Vietnam. Cancer Control. 2019;26(1).

9. Akhtari-Zavare M, Ghanbari-BaghestanA, LatiffahAL. Knowledge and belief towards breast cancer and breast self examination preactice among lanian women in Hamadan Iran. Asian Pac J Cancer Prev. 2014;15(16):6531-6534.

10. Mehrnoosh Akhtari-Zavare, Muhamad Hanafiah Juni, Irmi Zarina Ismail. Barriers to breast self examination practice among Malaysian female students: a cross sectional study. SpringerPlus.

11. Sami Abdo radman Al-DubaiSami Abdo radman Al-Dubai, Kurubaran Ganasegeran, Aied Mohammed Alabsi. Exploration of Barriers 
to Breast-Self Examination among Urban Sectional Study. Asian Pac J Cancer Prev. Women in Shah Alam, Malaysia: A Cross 2012;13:1627-1632.

\section{Summary \\ BREAST SELF-EXAMINATION PRACTICES AMONG WOMEN IN TIEN PHUONG COMMUNE IN 2020}

This study aimed to describe the prevalence of breast self-examination practices (BSE) and barriers to BSE among women in Tien Phuong commune, Chuong My District, Ha Noi city in 2020. A structured questionnaire was used to interview 353 women. The majority of the participants (70.9\%) reported no symptoms of breast-related disease. A little less than half of the participants reported performing some BSE (47.5\%), 60.4\% did not know how to do BSE, and only $3.7 \%$ correctly performed BSE. Univariate analysis showed that literacy, career, and number of children were significantly associated with the practice of breast self-examination. In conclusion, it is recommended to have public health education programs to raise awareness of breast cancer and BSE.

Keywords: Breast self-examination, BSE, breast cancer. 